\title{
Development of Vaccine Prototype Against Zika Virus Disease of Peptide-Loaded PLGA Nanoparticles and Evaluation of Cytotoxicity
}

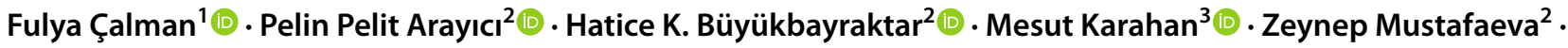 \\ Ramaz Katsarava ${ }^{4}$ iD
}

Accepted: 18 August 2018 / Published online: 25 August 2018

○) Springer Nature B.V. 2018

\begin{abstract}
Zika virus has recently evolved from an obscure mosquito-borne pathogen to an international public health concern. People with Zika virus disease can have indications including mild fever, skin rash, conjunctivitis, muscle pain, malaise or headache. Effective vaccines are needed for controlling and preventing the disease. In the current study, we aim to design the substructure for vaccine against Zika virus by forming antigenic peptide epitope of the disease. Zika peptide loaded poly (lactic-co-glycolic acid) (PLGA) nanoparticles have been fabricated in the present work as a potential artificial vaccine. UV and FT-IR Spectrophotometers and ZetaSizer were used for studying the nanoparticles, and Scanning Electron Microscope was used for morphological examination. The nanoparticles (NPs) yield, encapsulation efficiency, the peptide loading capacity were determined and in vitro release of the peptide was studied. Cytotoxic effects of the various concentrations of Zika peptide, blank PLGA nanoparticles and Zika peptide loaded PLGA nanoparticles on ECV304 human epithelial cells were determined via MTT assay. The present paper could be considered as one of the important steps in the use of nanoparticles for constructing the new generation of vaccination systems.
\end{abstract}

Keywords Nanoparticles $\cdot$ Peptide $\cdot$ PLGA $\cdot$ Vaccine $\cdot$ Zika virus $\cdot$ Cytotoxicity

\section{Introduction}

Zika virus is an arbovirus infection as well as a Flavivirus type and a Spondweni group RNA virus (Cook and Holmes 2006; Gatherer and Kohl 2016; Kuno et al. 1998). Firstly, it was isolated from Rhesus Monkeys in Zika Forest, Uganda, 1947. Culicidae family and Aedes type mosquitoes are the

Mesut Karahan

mesut.karahan@uskudar.edu.tr

1 Polymer Science and Technology Department, Institute of Pure and Applied Sciences, Marmara University, 34722 Istanbul, Turkey

2 Chemical and Metallurgy Faculty, Bioengineering Department, Yildiz Technical University, 34220 Istanbul, Turkey

3 Biomedical Devices Department, Vocational School of Health Services, Uskudar University, 34662 Istanbul, Turkey

4 Institute of Chemistry and Molecular Engineering, Agricultural University of Georgia, Kakha Bendukidze University Campus, No.240 David Agmashenebeli Alley, Tbilisi, Georgia most important vectors that spread of the disease. It has been isolated from Aedes aegypti mosquitoes within Aedes type and, revealed that these types can cause Zika virus transmission with experimental basal infections (Dick 1952; Rodriguez-Morales et al. 2016). Zika virus is particularly active in pregnant women and causes microcephaly. Microcephaly is a neurological status that causes baby's head to be small and can result in mental deficiency, hearing loss, vision loss, and seizures in new born babies (Brito 2016; Can et al. 2016). Furthermore, it is thought that apart from microcephaly Zika virus can cause Guillain-Barré Syndrome. Guillain-Barré Syndrome is a rarely observed peripheral nervous system and autoimmune disease that occurs when the immune system damages the nerve cells. This syndrome shows with critical symptoms such as numbness at the fingertips of hands and toes, weakness or sluggishness in the muscles, paralysis and even respiratory arrest, permanent nerve damage (Hughes and Cornblath 2005). There are no drugs or vaccines against Zika virus (Hughes and Cornblath 2005; WHO 2017) However, the search for vaccines continues. In vaccination studies of the disease, new generation vaccines such as recombinant DNA vaccines, synthetic peptide 
vaccines and mutant vaccines are being studied because of the disadvantages of classical vaccines, such as local reactions, the need to use large and multiple doses, and infection (Can et al. 2016; Yilmaz et al. 2016).

Peptides are constructs that could be used as antigen of vaccines. They are obtained synthetically and could easily be purified. However, synthetic peptides have small molecular size and low antigenicity and therefore need to be supported with carrier. Protein/polymer nano/micro particles as carrier for peptide provide higher immune response and improve the efficiency of vaccines (Derman et al. 2014; Mustafaeva 2016; Sümer 2011). Numerous studies have been carried out on the applications of NPs in biotechnology, medicine and biochemistry (Brito 2016; Derman et al. 2013; Owens and Peppas 2006).

NPs are prepared using both naturally occurring and synthetic polymers. The sizes of the polymeric nanoparticles range from 10 to $1000 \mathrm{~nm}$. The reasons for NPs to be so important are as follows: quantum size effects, size dependence of electronic structure, unique characteristics of surface atoms, and high surface/volume ratio. Advantages of nanoparticles arise from two basic properties (Derman et al. 2013; Miller et al. 2004; Rao et al. 2005). Firstly, owing to small sizes the NPs are taken into the cell via small capillaries and accumulates active matter in the target area. Secondly, various biomaterials including biodegradable ones are used for fabricating NPs. These materials release the active substance in a controlled manner on the target tissue during days and weeks. In addition to these advantages, NPs provide increased stability of preparations and simplicity of sterilization as well as increased distribution of active substance into the cells owing to a high loading capacity. Biodegradable NPs were used for drug and gene delivery to cells and tissue (Panyam and Labhasetwar 2003). Poly (lactic-co-glycolic acid) (PLGA) nano/micro particles (NPs/ MPs) play an important role in the next generation of vaccine delivery systems (Allahyari and Mohit 2016) PLGANPs induce a stronger immune response in vivo as a peptide carrier (Ma et al. 2012).

We assumed that the incorporation of the Zika peptide into the biodegradable NPs will provide increased bioavailability and releasing the peptide after administration of the NPs. Nanoparticles bearing antigenic molecules have been demonstrated to be promising in immunology. Zika virus's antigenic peptides were also used in such kind of studies. The general aim of these studies is to develop an immunogenic, peptide-based nanoparticle vaccine that is easily produced, stable, does not require a cold chain and is safe to use (Poland et al. 2018) Yu et al. reported that Zika peptide is active in such constructions (Yu et al. 2017). The peptide epitope W-DAHAKRQTVVVLGSQEGAV sequences which this peptide sequence found in silico approaches in literature was using as a model in this study (Can et al. 2016;
Kuno and Chang 2007). These publications showed that Zika peptide could be considered as a primarily solution in the world for producing the Zika vaccine.

For constructing the NPs loaded with the Zika peptide as a biodegradable polymer we have selected poly (lactic-coglycolic acid) (PLGA) which is a biodegradable polymer composed of nontoxic building blocks-lactic and glycolic acids. This polymer is frequently used as a matrix in many controlled drug release constructs (Derman et al. 2013).

The present paper deals with the preparation of the Zika peptide loaded PLGA NPs. The NPs were fabricated using double emulsion method. The NPs were characterized by sizes, zeta potential and polydispersity index. In addition, peptide loading capacity, produced nanoparticle yield and encapsulation efficiency were calculated, as well as in vitro peptide release studies were performed. In vitro cytotoxicity studies of the NPs showed they are biocompatible. The paper represents the first step of our planned systematic study for creating effective prototype of vaccine against Zika virus.

\section{Materials and Method}

\section{Materials}

Poly (lactic-co-glycolic acid) (PLGA) (lactic to glycolic acid ratio in the copolymer is 50:50, inherent viscosity $0.45-0.60$ $\mathrm{dL} / \mathrm{g}, \mathrm{M}_{\mathrm{w}}-38-54 \mathrm{kDa}$ ), polyvinyl alcohol (PVA), dichloromethane (DCM) were purchased from Sigma-Aldrich (St. Louis, Mo, USA). Ultra-pure water was acquired from Millipore Milli Q Gradient system.

The peptide epitope W-DAHAKRQTVVVLGSQEGAV sequences containing the antigenic characteristic in the Zika virus protein was synthesized with the peptide synthesizer using microwave energy and solid phase peptide synthesis method at the Yildiz Technical University as applied in our previous studies (Arayici et al. 2017; Karahan 2017). The tryptophan amino acid was added to the $\mathrm{N}$-terminus of the peptide as a fluorescent probe to provide subsequent fluorescence assays. Preparative HPLC and LC-MS devices were used for the purification and characterization of the peptide.

\section{Methods}

\section{Preparation of PLGA Nanoparticles}

Synthesized PLGA nanoparticles were fabricated using double emulsion (w/o/w) solvent evaporation method. (Feczkó et al. 2011; Vandervoort and Ludwig 2001; Yin et al. 2006). In this method, $2 \mathrm{mg}$ of the synthetic peptide was dissolved in $1 \mathrm{~mL}$ of pure water, and $150 \mathrm{mg}$ of the polymer was dissolved in $2 \mathrm{~mL}$ of dichloromethane (DCM). Composed w/o solution was added to $4 \mathrm{~mL}$ of $3 \%$ polyvinyl alcohol 
(PVA) solution in water, sonicated in ice bath 3-4 min at 50W (Bandelin Sonopuls, Germany). The mixture was stirred overnight on a magnetic stirrer and the solvent was removed by evaporation. The particles (ZNPs) were collected by centrifugation for $30 \mathrm{~min}$ at $10,000 \mathrm{rpm}$, washed three times with ultrapure water and after each centrifugation supernatant was removed. Solid nanoparticles were lyophilized and stored. Blank PLGA nanoparticles (BNPs) were obtained by the same double emulsion $(\mathrm{w} / \mathrm{o} / \mathrm{w})$ solvent evaporation method similar to the peptide-loaded nanoparticles, ZNPs. The only difference is that pure water was added instead of the peptide pure water solution used for fabricating ZNPs.

\section{Characterization of the NPs}

The obtained ZNPs and BNPs were characterized by size (Mean Particle Diameter), size distribution (Polydispersity Index, PDI), and zeta potential (ZP), which were assessed by Dynamic Light Scattering (DLS) using a particle size analyzer (Zetasizer Nano ZS, Malvern Instruments, Malvern, UK). Measurements were performed three times using $0.8872 \mathrm{cP}$ viscosity and 1.330 refractive index for the solutions, dielectric constant 79; $\mathrm{f}(\mathrm{ka}) 1.50$ (Smoluchowski) at $25^{\circ} \mathrm{C}$. Before the measurement the suspensions were diluted with pure water.

\section{Fourier Transform Infrared Spectroscopy (FTIR) Measurement of the NPs}

FTIR spectrum is a characterization technique that uses to identify organic compound in the structure. With this technique, the vibrational frequencies of the various bonds in the structure are measured to provide information about the functional groups in the analyzing compound. Infrared spectra of ZNPs, BNPs and the peptide were recorded with IRPrestige 21 FTIR spectrophotometer (Shimadzu, Japan) in universal attenuation total reflectance (ATR) mode.

\section{Calculations of Nanoparticles Yield, Encapsulation Efficiency and Peptide Loading}

Nanoparticles yield (NPY) calculation for ZNPs and BNPs was made using the following formula.

NPY $(\%)=\frac{\text { Amount of produced nanoparticles }(\mathrm{mg})}{\text { Total amount of initial peptide and PLGA }(\mathrm{mg})} \times 100$

Calculation of the encapsulation efficiency (EE) of the peptide in ZNPs and degree of loading (DL) was done using the calibration curve of the peptide at $280 \mathrm{~nm}$ wavelength (Model UV1700 Pharma-Sec, Shimadzu, Japan). The calculation was made using the following formula:
$\mathrm{EE}(\%)=\frac{\text { Encapsulated peptide amount }(\mathrm{mg})}{\text { Total amount of peptide initially } \operatorname{added}(\mathrm{mg})} \times 100$

Peptide loading capacity (Degree of loading, DL) was calculated by the following formula:

$\mathrm{DL}(\%)=\frac{\text { Encapsulated peptide amount }(\mathrm{mg})}{\text { Amount of produced nanoparticles }(\mathrm{mg})} \times 100$

\section{Analysis of Scanning Electron Microscope (SEM)}

Morphological analysis of the NPs was carried out using scanning electron microscope (SEM, Zeiss, EVO-LS 10). The lyophilized ZNPs and BNPs were gold-coated $5 \mathrm{kV}$ acceleration voltage was used for SEM photomicrographs.

\section{In vitro Peptide Release}

The lyophilized ZNPs were dispersed in phosphate buffered saline at $\mathrm{pH} 7.4$ (PBS) $-0.01 \%$ sodium azide as release medium. The same process was applied to the lyophilized BNPs. Peptide release was carried out at $37{ }^{\circ} \mathrm{C}$ in a shaker at $150 \mathrm{rpm}$. The suspension was centrifuged and supernatant completely removed at certain time intervals such as $1,2,3$, 4, 5, 6, 48, 144, 180, 200, $264 \mathrm{~h}$ and fresh release medium was added to solid nanoparticles pellet after each centrifugation. The amount of released peptide in the supernatant was calculated using the calibration curve of the peptide at $280 \mathrm{~nm}$ wavelength.

\section{Cell Viability Assay}

The cytotoxicity test of MTT [3-(4,5-dimethylthiazol2-yl)-2,5-diphenyl tetrazolium bromide] was performed to determine the cytotoxic effects of the peptide, peptide loaded PLGA nanoparticles, ZNPs, and blank PLGA nanoparticles, BNPs. For testing, ECV304 human epithelial cells were used. ECV304 cells were incubated at $37^{\circ} \mathrm{C}$ with $5 \%$ $\mathrm{CO}_{2}$ in DMEM medium containing penicillin/streptomycin, L-glutamine and 10\% Fetal Bovine Serum (FBS). ECV 304 named epithelial cells were counted using Thoma slides. A 96-well plate was seeded to 100,000 cells per $\mathrm{mL}$. It was incubated for 1 day. $500 \mu \mathrm{g} / \mathrm{mL}$ of peptide, blank nanoparticle and peptide loaded nanoparticle stocks were prepared. $10 \mu \mathrm{L}$ of DMEM was added to each well and 50, 10, 5, 1 dilutions of the ZNPs, BNPs, and peptide were added. Afterwards, $10 \mu \mathrm{L}$ of MTT solution was added to each well. Culture platelets were incubated in the dark at $37{ }^{\circ} \mathrm{C}$ incubator containing $5 \% \mathrm{CO}_{2}$ for $3 \mathrm{~h}$. Then $80 \mu \mathrm{L}$ of DMEM was removed from the sides of the wells without damaging the cells. To each well $100 \mu \mathrm{L}$ of $50 \%$ DMSO mixed with isopropyl alcohol was added and incubated for $45 \mathrm{~min}$. The 
subsequent spectrophotometric measurements were done at $570 \mathrm{~nm}$ wavelength.

\section{Results and Discussion}

Zika is a disease caused by the Zika virus which is a RNA virus from the FLAVIVIRUS group and transmitted to people through mosquito bites. The differential diagnosis is broadened because of typical clinical manifestation. It is being confused with Dengue, Chikungunya, Malaria, Rickettsia, Measles, and Rubella diseases. The severity of Zika virus infection urged World Health Organization (WHO) to state this virus as a global concern and about 1 out of every 5 people who are infected with Zika virus are ill and develop symptoms. It is often a silent infection that is difficult to diagnose. It is diagnosed via virus isolation from polymerase chain reaction mechanism or blood sample. People who are infected with Zika virus are not offered a specific antiviral drug because there is no treatment or vaccination against Zika virus. The limited knowledge on the structure, virulent factors, and replication mechanism of the virus pose as hindrance for vaccine development. In this study, Zika disease was selected considering all these factors.

The fabrication of peptide-loaded poly (lactic-co-glycolic) acid (PLGA) NPs was performed with the synthetic peptide. According to Derman and Mustafaeva's researches (Arasoglu et al. 2016; Derman et al. 2015; Mustafaeva 2017), PLGA NPs are advantageous in drug release process because of the small particle size and controlled release profile of bioactive molecules, improved distribution in water medium bioavailability, biocompatibility, ability to be degraded into non-toxic products To date the PLGA is one of the most widely used biodegradable polymer approved by the FDA.

\section{NPs Yield, Encapsulation Efficiency and Peptide Loading of Nanoparticles}

In the study, the peptide was loaded in PLGA nanoparticle by double emulsification solvent evaporation method. The nanoparticles produced were characterized respectively RY, EE and DL as discussed above. The results obtained are shown in Table 1. In addition, the peptide loading capacity of the nanoparticle increases with increasing initial peptide content, while the reaction yield of nanoparticle decreases with increasing amount of peptide (Mustafaeva 2017).

The size, zeta potential and polydispersity index (PDI) of the obtained NPs were performed using a nano Zetasizer. The size distributions and zeta potential of the NPs are shown in Figs. 1 and 2; the particle size, zeta potential and PDI values are given in Table 1 . The zeta potential of the NPs is within $-16.9 \pm 0.458$ and $-16.3 \pm 0.208$. The reason for negative values of the zeta potential could be ascribed to the ionized carboxyl groups appeared after a partial hydrolysis of the ester groups of the PLGA matrix. High values of the charges (positive or negative) prevent agglomeration
Table 1 The basic characteristics of the obtained NPs

\begin{tabular}{lllllll}
\hline & $\begin{array}{l}\text { NPs yield, } \\
\text { NPY, } \%\end{array}$ & $\begin{array}{l}\text { Encapsulation } \\
\text { efficiency, EE, } \%\end{array}$ & $\begin{array}{l}\text { Peptide loading } \\
\text { capacity, DL, } \%\end{array}$ & $\begin{array}{l}\text { NPs average } \\
\text { size }(\mathrm{nm}) \pm \text { SD }\end{array}$ & $\begin{array}{l}\text { Zeta potential, } \\
\text { ZP }(\mathrm{mV}) \pm \text { SD }\end{array}$ & PDI \pm SD \\
\hline ZNP & 63.6 & 85.0 & 1.76 & $250.4 \pm 2.532$ & $-16.9 \pm 0.458$ & $0.118 \pm 0,024$ \\
BNP & 87.2 & - & - & $211.9 \pm 1.819$ & $-16.3 \pm 0.208$ & $0.036 \pm 0,018$ \\
\hline
\end{tabular}

Analysis of the NPs size, Zeta potential and PDI
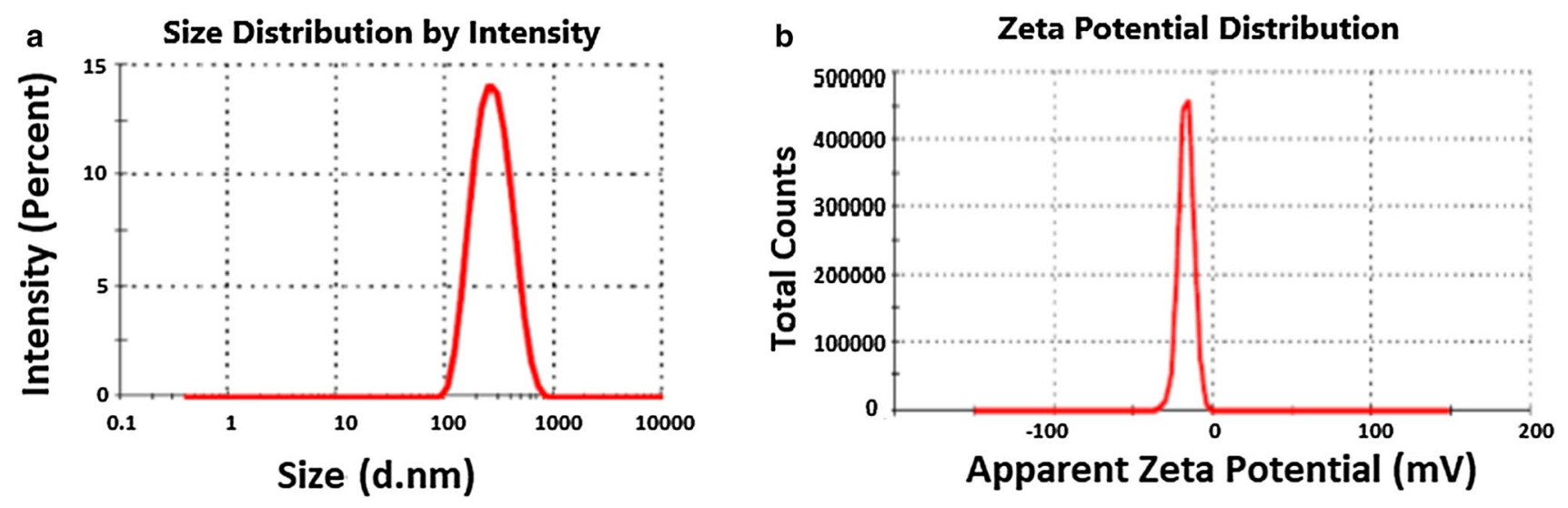

Fig. 1 The particles size (a) and zeta potential (b) distribution of the ZNPs 

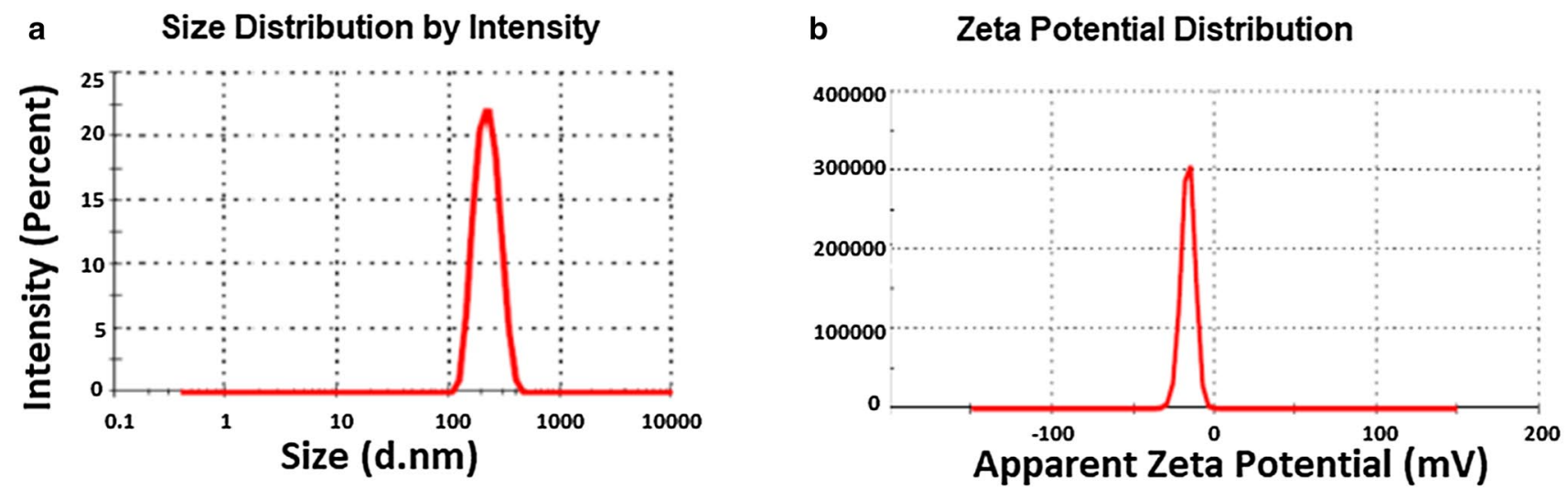

Fig. 2 The particles size (a) and zeta potential (b) distribution of the BNPs

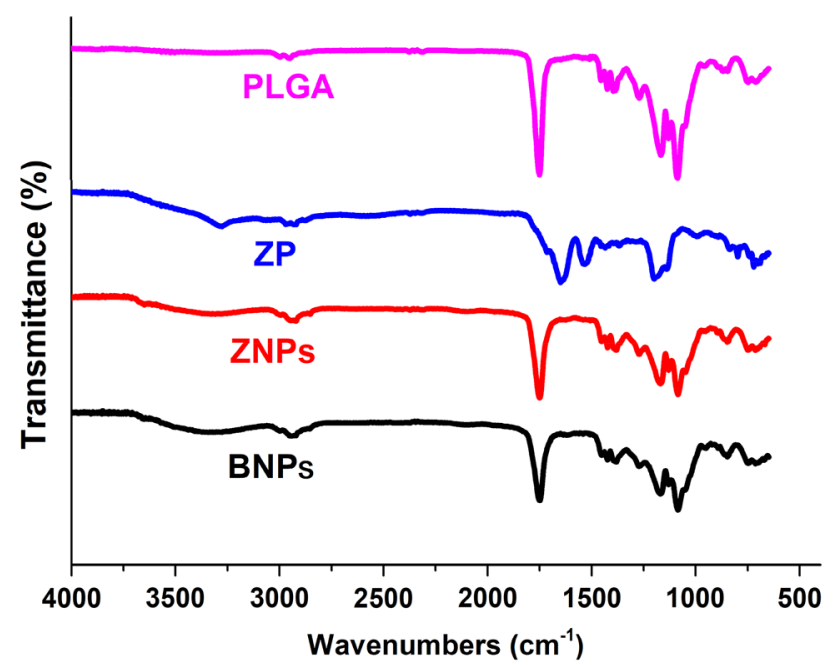

Fig. 3 FTIR spectra of the blank NPs (BNPs), Zika peptide loaded NPs (ZNPs), Zika peptide (ZP), and PLGA polymer

and provide long-term stability of the NPs (Arasoglu et al. 2016).

\section{FTIR Analysis of the NPs}

As shown in Fig. 3, PLGA molecule showed peaks such as carbonyl $-\mathrm{C}=\mathrm{O}$ stretching $\left(1751 \mathrm{~cm}^{-1}\right), \mathrm{C}-\mathrm{O}$ stretching $\left(1087 \mathrm{~cm}^{-1}\right)$. Pure peptide sample demonstrated amide $\mathrm{C}=\mathrm{O}$ stretching $\left(1660 \mathrm{~cm}^{-1}\right)$. When the obtained spectra are compared, it is seen that the FTIR spectra of ZNP and BNP show the same chemical characteristics. In the FTIR spectrum of ZNP peptide-loaded nanoparticles, the main peak of peptide at $1660 \mathrm{~cm}^{-1}$ was conspicuously decreased that can be ascribed to a low concentration of the peptide. Thus, peptide was successfully loaded to PLGA nanoparticles (Arasoglu et al. 2016; Derman et al. 2015; Mustafaeva 2017).

\section{Scanning Electron Microscope (SEM) Analysis of the NPs}

SEM images of the NPs given in Fig. 4 show that ZNPs are obtained with spherical shapes and rather smooth and narrow size distribution (Mustafaeva 2017; Derman et al. 2015). It has to be noted that particles sizes obtained from SEM (Fig. 4) and DLS studies (Table 1) well coincide. Based on these data we can conclude that ZNPs of both desirable size and morphology have been successfully obtained.

\section{In vitro Peptide Release}

Peptide release studies were performed with dialysis membrane in PBS (pH 7.4) and the resulting release profile is shown in Fig. 5. Controlled release of the peptide was studied during 11 days. A high degree of release was observed within the first two days (20.6\%). After this and during 8 days the cumulative release of the peptide reached a plateau, i.e. no farther release was observed.

\section{Determination of Cell Viability}

The cell viability graphs obtained for the peptide, ZNPs and BNPs at various concentrations are depicted in Fig. 6. The peptide showed almost no toxic effect at the concentrations of 1 and $5 \mu \mathrm{g} / \mathrm{mL}$. At the concentrations 10 and $50 \mu \mathrm{g} / \mathrm{mL}$, cell viability decreased by $c a$. $22 \%$ and $28 \%$. The BNPs showed that within the studied concentration range $(1-50 \mu \mathrm{g} /$ $\mathrm{mL}$ ) the pure polymer is nontoxic. The ZNPs are less toxic within the concentration range $1-10 \mu \mathrm{g} / \mathrm{mL}$. At a concentration of $50 \mu \mathrm{g} / \mathrm{mL}$ cell viability is reduced. Comparison of the data obtained with the BNPs and ZNPs showed that the excipients had a low cytotoxic effect. In whole, the experiments show that ZNPs we plan to use as a vaccine prototype is of low toxicity. These data confirmed that ZNP possesses a good efficacy against ECV304 human epithelial cells. 

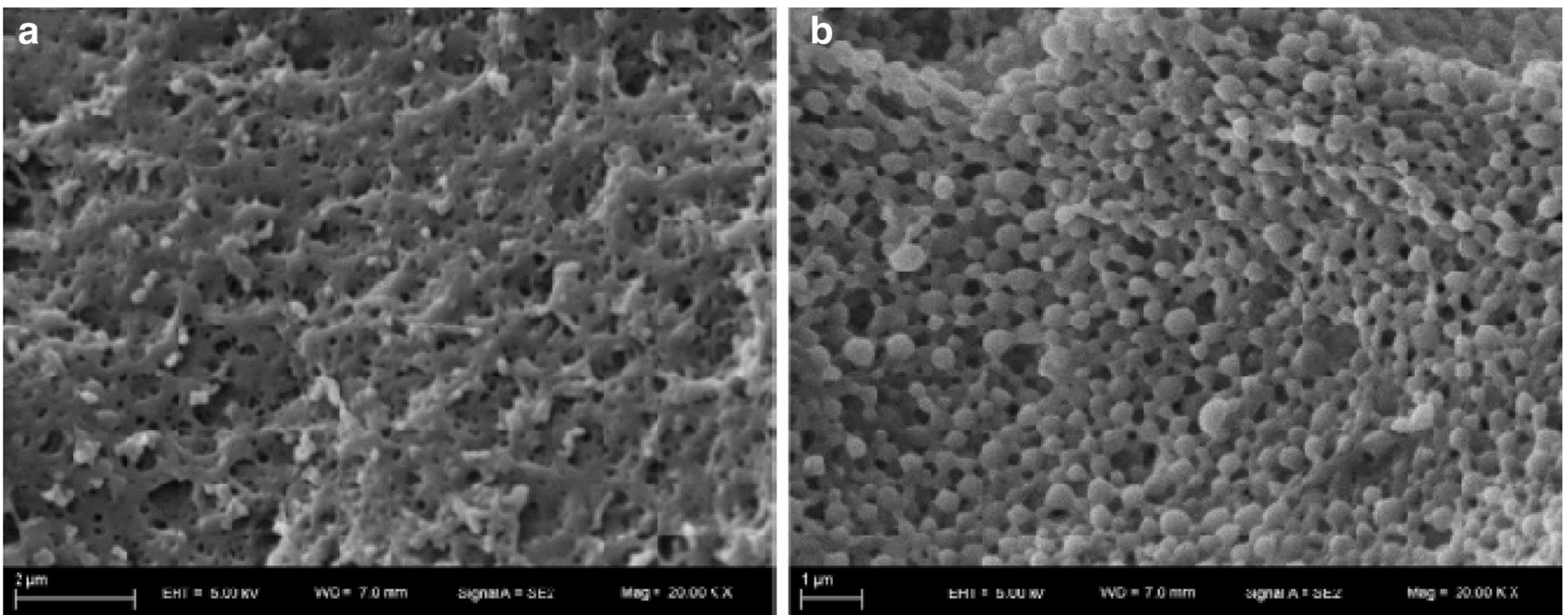

Fig. 4 SEM image of (a) BNPs and (b) ZNPs (20.00 K X)

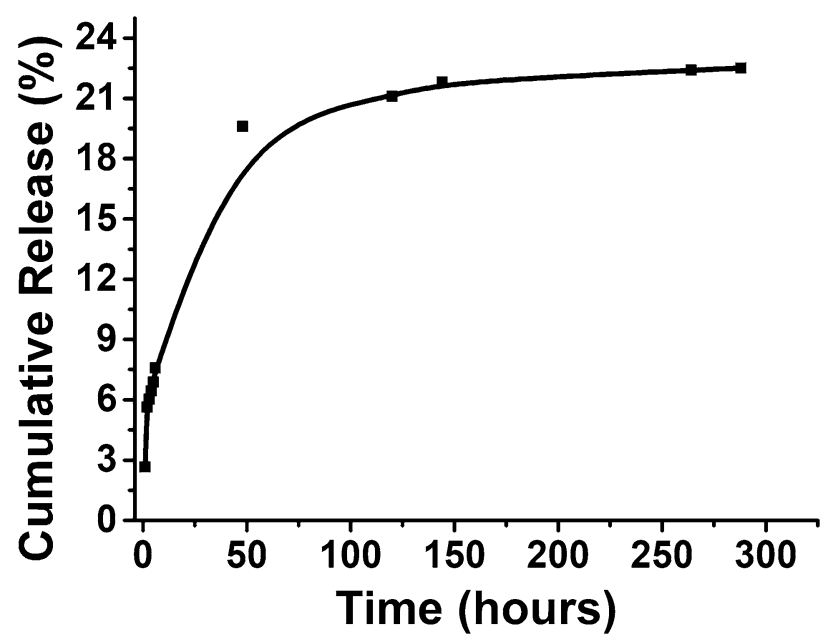

\section{Conclusion}

We have performed a successful production of the PLGA nanoparticles both the blank nanoparticles, BNPs, and loaded with Zika virus antigenic peptide epitope, ZNPs. Both types of the NPs were fabricated using the double emulsion/solvent evaporation method. The obtained NPs were characterized with nano ZetaSizer, FTIR spectroscopy and SEM. The NPs yield, encapsulation efficiency and the peptide loading capacity were determined and cumulative release of the peptide was studied during 11 days. Non-toxic concentration range of the ZNPs was determined. Detailed immunization studies of the obtained new artificial vaccine are in progress now.

Fig. 5 Release profiles of the peptide from the ZNP in PBS ( $\mathrm{pH} 7.4$ ) solution containing $0.01 \%$ of sodium azide

Fig. 6 Cell viability graphs for the peptide, ZNPs and BNPs

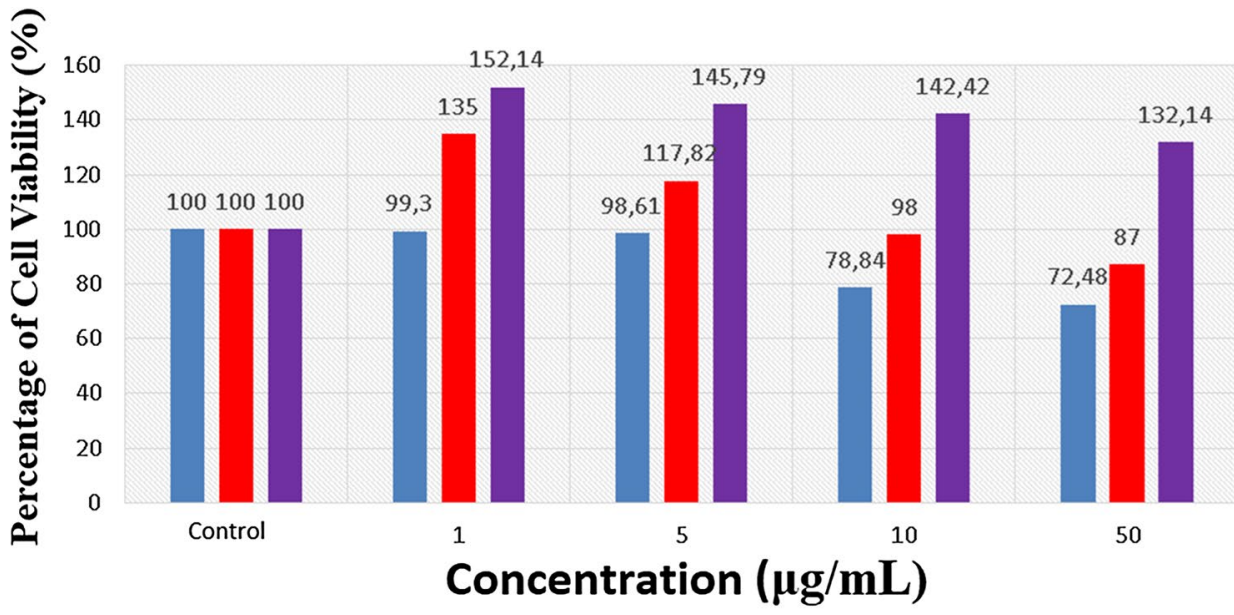

- Cell viability for peptide - Cell viability for ZNP =Cell viability for BNP 
Acknowledgements The authors wish to thank the Scientific and Technological Research Council of Turkey (TUBITAK) for its support and contribution as part of the 2209-A University Student Domestic Research Projects Support Program.

\section{Compliance with Ethical Standards}

Conflict of interest All author declares that they have no conflict of interest.

Research Involving Animal and Human Participants This article does not contain any study with human or animal subjects performed by any of the authors.

\section{References}

Allahyari M, Mohit E (2016) Peptide/protein vaccine delivery system based on PLGA particles. Hum Vaccine Immunother 12:806-828

Arasoglu T, Derman S, Mansuroglu B (2016) Comparative evaluation of antibacterial activity of caffeic acid phenethyl ester and PLGA nanoparticle formulation by different methods. Nanotechnology 27:025103. https://doi.org/10.1088/0957-4484/27/2/025103

Arayici PP, Acar T, Maharramov AM, Karahan M, Mustafaeva ZA (2017) Synthesis and characterization of bioconjugates of antigenic rabies virus peptide epitope with polyacrylic acid. Fresen Environ Bull 26:2752-2758

Brito C (2016) Zika virus: a new chapter in the history of medicine. Acta Med Port 28:679-680

Can F, Arayici-Pelit P, Karahan M, Mustafaeva Z, Mamedov B (2016) The current approaches to Zika virus vaccination. Biotechnol Acta 9:7-13. https://doi.org/10.15407/biotech9.04.007

Cook S, Holmes E (2006) A multigene analysis of the phylogenetic relationships among the flaviviruses (Family: Flaviviridae) and the evolution of vector transmission. Arch Virol 151:309-325. https://doi.org/10.1007/s00705-005-0626-6

Derman S, Kızılbey K, Akdeste ZM (2013) Polymeric nanoparticles. Sigma J Eng Nat Sci 31:107-120

Derman S, Kizilbey K, Mansuroglu B, Mustafaeva Z (2014) Synthesis and characterization of canine parvovirus (CPV) VP2 W-7L20 synthetic peptide for synthetic vaccine. Fresen Environ Bull 23:558-566

Derman S, Mustafaeva ZA, Abamor ES, Bagirova M, Allahverdiyev A (2015) Preparation, characterization and immunological evaluation: canine parvovirus synthetic peptide loaded PLGA nanoparticles. J Biomed Sci 22:89

Dick G (1952) Zika virus (II). Pathogenicity and physical properties. Trans R Soc Trop Med Hyg 46:521-534

Feczkó T, Tóth J, Dósa G, Gyenis J (2011) Optimization of protein encapsulation in PLGA nanoparticles. Chem Eng Process 50:757-765

Gatherer D, Kohl A (2016) Zika virus: a previously slow pandemic spreads rapidly through the Americas. J Gen Virol 97:269-273. https://doi.org/10.1099/jgv.0.000381
Hughes RA, Cornblath DR (2005) Guillain-barre syndrome. The Lancet 366:1653-1666. https://doi.org/10.1016/S0140 $-6736(05) 67665-9$

Karahan M (2017) Antigenic peptide synthesis and characterization of Q fever disease. AKU-J Sci Eng 17:312-317. https://doi. org/10.5578/fmbd.53815

Kuno G, Chang G-J (2007) Full-length sequencing and genomic characterization of Bagaza, Kedougou, and Zika viruses. Arch Virol 152:687-696

Kuno G, Chang G-JJ, Tsuchiya KR, Karabatsos N, Cropp CB (1998) Phylogeny of the genus Flavivirus. J Virol 72:73-83

Ma W et al (2012) PLGA nanoparticle-mediated delivery of tumor antigenic peptides elicits effective immune responses. Int J Nanomed 7:1475-1487

Miller JC, Serrato R, Represas-Cardenas JM, Kundahl G (2004) The handbook of nanotechnology: business, policy, and intellectual property law. Wiley, Hoboken

Mustafaeva Z (2016) polymers in vaccine formulation. Sigma J Eng Nat Sci 34:439-451

Mustafaeva Z (2017) Synthesis and characterization of poly(lactic-coglycolic-acid) microparticles loaded with foot-and-mouth disease virus 40-60 synthetic peptide. Biotechnol Acta 10:52-60. https:// doi.org/10.15407/biotech10.01.052

Owens DE, Peppas NA (2006) Opsonization, biodistribution, and pharmacokinetics of polymeric nanoparticles. Int J Pharm 307:93-102

Panyam J, Labhasetwar V (2003) Biodegradable nanoparticles for drug and gene delivery to cells and tissue. Adv Drug Deliv Rev 55:329-347

Poland GA, Kennedy RB, Ovsyannikova IG, Palacios R, Ho PL, J K (2018) Development of vaccines against Zika virus. Lancet Infect Dis 18:e211-e219. https://doi.org/10.1016/S1473-3099(18)30063 $-X$

Rao CNR, Müller A, Cheetham AK (2005) The chemistry of nanomaterials, vol 1. Wiley, Hoboken

Rodriguez-Morales AJ, Bandeira AC, Franco-Paredes C (2016) The expanding spectrum of modes of transmission of Zika virus: a global concern. Ann Clin Microbiol Antimicrob 15:13. https:// doi.org/10.1186/s12941-016-0128-2

Sümer Z (2011) Immunological basis of vaccination. Turkiye Klinikleri J Fam Med 2:19-22

Vandervoort J, Ludwig A (2001) Preparation factors affecting the properties of polylactide nanoparticles: a factorial design study. Pharmazie 56:484-488

WHO (2017) Zika virus. http://www.who.int/mediacentre/factsheets/ zika/en/. Accessed 10 May 2017

Yilmaz E, Arayici P, Maharramov A, Mustafaeva Z (2016) Approaches to designing of new generation vaccines against the sheep pox disease. Biotechnol Acta 9:7-15. https://doi.org/10.15407/biote ch9.06.007

Yin Y, Chen D, Qiao M, Lu Z, Hu H (2006) Preparation and evaluation of lectin-conjugated PLGA nanoparticles for oral delivery of thymopentin. J Control Release 116:337-345

Yu Y et al (2017) A peptide-based viral inactivator inhibits Zika virus infection in pregnant mice and fetuses. Nat Commun 8:15672 